\title{
Reproductive success of the threatened Reed Parrotbill Paradoxornis heudei in non-harvested and harvested reedbeds in the Yangtze River estuary, China
}

\author{
ANTHONY BOULORD, ZHANG MEI, WANG TIAN-HOU, WANG XIAO-MING \\ and FRÉDÉRIC JIGUET
}

\begin{abstract}
Summary
Understanding the factors that affect the nesting success of threatened birds is essential in designing effective conservation strategies. Here we compare nesting success of the Reed Parrotbill Paradoxornis heudei in annually harvested and non-harvested reedbed habitats in the Chongming Dongtan Nature Reserve in China, by recording the number of nestlings produced per nest and the causes of nest failure. We modelled daily nest survival rate (DSR) by considering the effects of harvesting, vegetation characteristics, year, date, advancement within the breeding season, nest age and nearest-nest distance, using the program MARK. Nest densities, but not the number of fledglings per nest, were significantly lower in harvested than non-harvested reedbed habitats. The best-fit DSR model estimated constant survival; none of the tested co-variables had significant effects. Moreover, harvesting did not affect the date of breeding initiation, likelihood of nest failure, or causes of nest failure, as vegetation cover was not significantly different between harvested and non-harvested reedbeds during the whole breeding season. Nest failure following adverse weather conditions was unusually common in harvested and non-harvested reedbeds, accounting for as many nest failures as depredation. However, comparisons with other studies suggest that deriving a conclusion on the impact of harvesting on nesting success is not straightforward and is probably linked to environmental characteristics affecting reed growth.
\end{abstract}

\section{Introduction}

Harvesting of common reed Phragmites australis, a large perennial grass with great economic value, can help to maintain reedbed habitat because it prevents accumulation of organic material and thus colonisation by other plant species (Valkama et al. 2008). However, extensive stands of common reed are an important habitat for birds, including many rare and vulnerable species, which may be either positively or negatively affected by reed cutting (Bibby and Lunn 1982, Kristiansen 1998, Barbraud and Mathevet 2000, Boulord et al. 2010). Understanding the potential effects of harvesting on bird communities is thus important in enhancing reedbed management and balancing economic benefits and biodiversity conservation.

A recent review focusing on reedbed management in Europe concluded that bird numbers are $60 \%$ lower in harvested stands (Valkama et al. 2008). For species nesting early in the season, winter harvesting has been shown to reduce vegetation cover and prevent nesting (Baldi and Moskat 1995, Poulin and Lefebvre 2002), increase the risk of nest predation and delay clutch initiation (Graveland 1999), and decrease arthropod abundance which may affect food availability for birds (Graveland 1999, Poulin and Lefebvre 2002). 
Most published studies investigating the potential impact of reed harvesting on bird species have focused on breeding density (Kristiansen 1998, Barbraud and Mathevet 2000, Barbraud et al. 2002, Poulin and Lefebvre 2002, Trnka and Prokop 2006, Boulord et al. 2010) but very few have investigated demographic parameters. Of these parameters, reproductive success is of key importance to population viability (Haig et al. 1993), especially in species with short generation times. Understanding harvesting effects on reproductive success is therefore essential in designing reedbed management strategies that are compatible with the conservation of threatened species. Graveland (1999) showed that nesting success is higher in non-harvested than harvested reedbeds for European populations of Eurasian Reed Warbler Acrocephalus scirpaceus and Sedge Warbler A. schoenobaenus. However, a review by Valkama et al. (2008) did not support a generalisation of this pattern.

In this study, we quantify the effects of reed harvesting on the reproductive success of Reed Parrotbill Paradoxornis heudei, a passerine found in reedbeds of the lower Yangtze River, the Yellow Sea coast of north-east China, extreme eastern Mongolia and extreme south-east Russia (Zheng 2002). Its populations are declining, presumably because of habitat loss and degradation, and it is considered 'Near Threatened' (BirdLife International 2010). Individuals live in flocks during the winter, form pairs in April, and nest from early May to late September (Ma 1988). Population density is significantly higher in non-harvested than in harvested reedbeds during the breeding period (Boulord et al. 2010). Furthermore, Boulord et al. (2010) showed that individuals nest in tall reed stands, which are not always available in harvested areas. Our objectives were therefore to evaluate the potential impacts of reed harvesting on the nesting success of the Reed Parrotbill and to determine which environmental factors could mediate these effects.

\section{Materials and methods}

Field work was carried out during the 2009 and 2010 breeding seasons in the reedbeds of the Chongming Dongtan National Nature Reserve $\left(31^{\circ} 25^{\prime}-31^{\circ} 38^{\prime} \mathrm{N}, 121^{\circ} 50^{\prime}-122^{\circ} \mathrm{O} 5^{\prime} \mathrm{E}\right)$, a complex of coastal wetland ecosystems listed as a Wetland of International Importance by the Ramsar Convention. It is located on Chongming Island, Shanghai Municipality, China. The island has a subtropical monsoon climate with an average annual temperature of $15.3^{\circ} \mathrm{C}\left(26^{\circ} \mathrm{C}\right.$ in summer and $3^{\circ} \mathrm{C}$ in winter). Average humidity is $82 \%$ and average annual precipitation is approximately $1,022 \mathrm{~mm}$, with $60 \%$ of rainfall occurring between May and September (Tian et al. 2010). In July and August thunderstorms are frequent and wind speed often reaches level 4-5 on the Beaufort scale.

We chose two study areas $1.5 \mathrm{~km}$ apart, mainly composed of monospecific stands of common reed (Figure I). The first study area (NHA) consisted of a reedbed that remained non-harvested for at least two years. The total area is covered by monospecific stands of common reed with patches of smooth cordgrass Spartina alterniflora, an introduced species, that are not occupied by Reed Parrotbill (Boulord et al. 2010). The total area of common reed was 3.9 ha in 2009 and 4.2 ha in 2010. The second study area (HA) is a 5 ha monospecific stand of common reed which was completely harvested manually in February-March in each of the two consecutive study years. In both areas, water level was usually under $10 \mathrm{~cm}$, except during several days after heavy rain when water level reached $10-20 \mathrm{~cm}$.

\section{Nest monitoring}

In each area we searched for nests once a month, as each breeding attempt lasts at least 29 days (see below), from mid-May to late-August, by walking 3-m wide transects through reedbeds. Nest position was recorded with a GPS (Garmin Etrex ${ }^{\circledR}$ ) and contents were monitored every 3-4 days until fledging or nest failure. In cases of nest failure, adverse weather was considered to be the cause when eggs were found on the ground and/or the nest was found destroyed after strong winds. When eggshells were found in the nest, the nest was found destroyed, or young nestlings disappeared during a period with no strong winds, we considered the nest to have been predated. If cold eggs remained in the nest for several days, the nest was considered abandoned. We used 


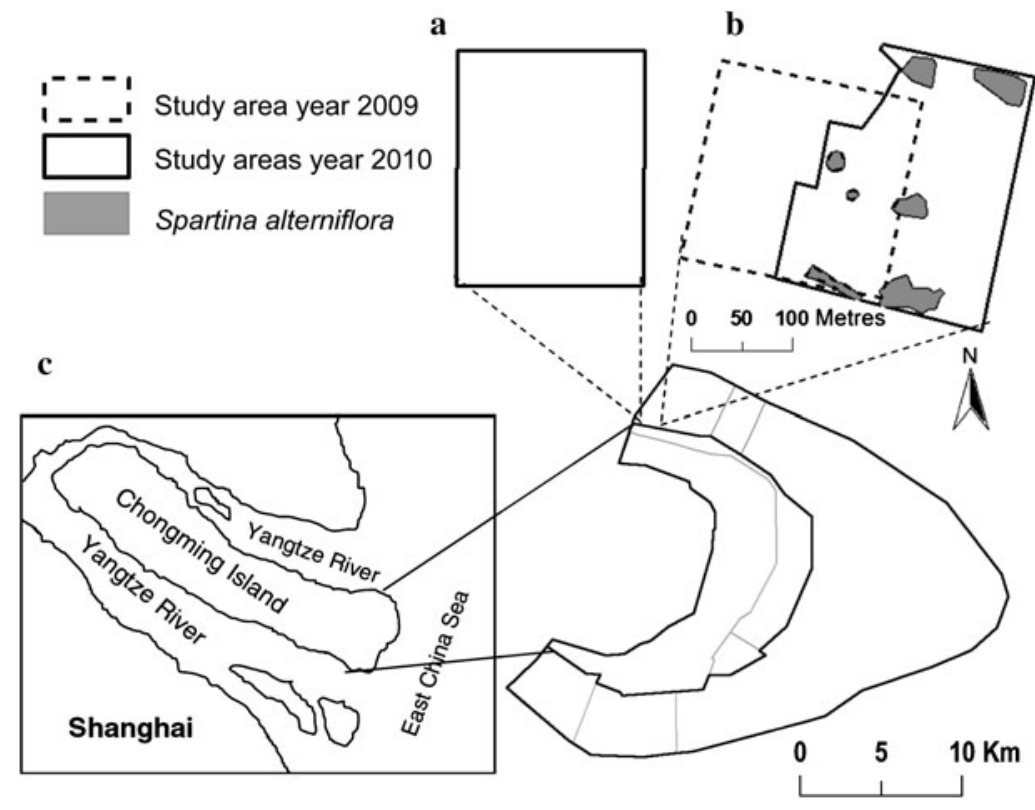

Figure 1. Locations of the harvested (a) and non-harvested (b) study areas in the Chongming Dongtan National Nature Reserve located in the Yangtze River (c)

chi-square tests to check for differences in causes of nest failure between years for the NHA, and between NHA and HA in 2010.

For each nest, the first laying day was determined by direct observation or back-dating on nests for which at least the beginning of one nesting stage was witnessed. Our previous research on the species allowed the duration of each nesting phase to be determined, so we used these phases (one day per egg for laying, 13 days for incubation and 12 for the nestling phase) to calibrate the back-dating.

Reed Parrotbill can raise three broods during the nesting season (Boulord pers. obs.). The first laying period occurs from mid-May to mid-July, the second from mid-July to mid-August and the third from mid-August to mid-September. We assigned each nest to a laying period. We also assigned nests that were found empty to one of these three laying periods, assuming that they were built between the dates of the previous and current nest surveys. Using this method, we assumed that there was no substitution attempt due to nest failure, so that the different nests of a laying period belonged to different pairs.

We divided the study areas into 50-m wide quadrats (four quadrats in 2009, five in 2010) and defined nest density in each quadrat by dividing the total number of nests per quadrat by the area of pure common reed. We tested for differences in nest densities between years for NHA, and between NHA and HA in 2010, with Student's t-tests. In order to examine whether harvesting was correlated with delays in nest initiation, we then used a chi-square test to test for an equal nest distribution among the three laying periods between years in the NHA, and between NHA and HA in 2010.

\section{Vegetation measurements}

Each study area was divided into three parallel transects ( $100 \mathrm{~m}$ long in 2009 and $200 \mathrm{~m}$ in 2010) separated by a width of $50 \mathrm{~m}$. In each transect, $50 \mathrm{~cm} \times 50 \mathrm{~cm}$ quadrats were placed at each $50 \mathrm{~m}$ 
interval (nine quadrats in 2009 in NHA and 15 quadrats in 2010 in NHA and HA). In each quadrat, densities of green stems (shoots of the year) and dry stems (shoots of previous years) were measured at the beginning of September. Each month, from June to August in 2009 and from May to August in 2010, heights of five randomly chosen green stems were measured in each quadrat. We measured the height at the last node of the stem and did not consider terminal leaves. Height of dry stems was measured in June 2009 and May 2010. We examined monthly differences in green stem heights between NHA and HA in 2010 with Bonferroni's correction. We chose green stems as they were taller than dry ones and presumably contribute more to vegetation cover. In the NHA in May, however, dry reed stems were taller than green stems; we thus included them in the dataset for that month.

\section{Nest survival and nesting success}

We estimated the Daily Survival Rate (DSR) of nests, i.e. the probability that a nest survives for one day, using the nest survival model in the program MARK (White and Burnham 1999, Dinsmore et al. 2002) following recommendations by Rotella (2009). We established 14 May as the first nest day. We defined two groups according to the year of study (2009 and 2010) and used the nest survival model to test for year, time (linear and quadratic) and nest-age (linear and quadratic) effects on DSR. We also tested for effects of the following covariates: habitat (NHA or HA), vegetation height, vegetation density (green stems in HA and sum of green and dry stems in NHA), distance from the nearest nest, and laying period. Vegetation height for each nest was defined as the mean green stem height measured in the nearest quadrat during the month in which laying was initiated. Vegetation density for each nest was defined as the density of reeds measured in the nearest quadrat. Distance from the nearest nest was measured between nests in the same laying period.

We first ran the model for each variable individually. The quality of each model was evaluated using Akaike's Information Criterion (AIC; Akaike 1973) in order to choose the best-fit model for hypothesis testing (Burnham and Anderson 1998, 2002). We used the AICc, a correction of AIC for small sample size (Dinsmore et al. 2002). Normalised Akaike weights $\left(\mathrm{w}_{\mathrm{i}}\right)$ were calculated to define the strength of evidence for each model (Burnham and Anderson 1998, 2002, Dinsmore et al. 2002). The model with the lowest AICc is considered to best fit the data; but, as suggested by Burnham and Anderson (2002), we retained all models with $\triangle \mathrm{AICc}<2$ to test models involving two covariates. Since time and laying period were correlated, we did not run a model including both covariates. As no model involving two covariates provided a better fit than those involving one covariate, we did not perform three-way interaction models.

Nest success, which is the true probability of a nest to survive from laying to fledging (Rotella 2009), was then estimated as following: nest success $=D^{d} \times 100$, where $d$ is the number of days from first laying date to fledging date (29 days on average) and DSR is the estimate obtained with the best fit model.

Nesting success not only depends on the nest fate but also on the number of chicks per nest that survived until fledging. We thus tested for inter-annual and inter-habitat differences in the numbers of surviving chicks produced per nest using Student's t-tests.

\section{Results}

\section{Nest density and nesting period}

We found a total of 46 and 70 nests in NHA in 2009 and 2010 respectively, and 46 nests in HA in 2010. In 2010, nest density was significantly higher in NHA $\left(16.4 \pm 5.6\right.$ nests ha $\left.^{-1}\right)$ than in HA ( $9.2 \pm 2.9$ nests ha $^{-1}$; Student's t-test, $t_{8}=-2.54, P=0.03$ ). In NHA, nest density was not significantly higher in $2010\left(16.4 \pm 5.6\right.$ nests $\left.^{-1}{ }^{-1}\right)$ than in 2009 (11.8 \pm 4.7 nests ha ${ }^{-1} ; t_{7}=-1.32$, $P=0.23)$. In 2009, the nesting period started in the first week of June in NHA. In 2010, the 


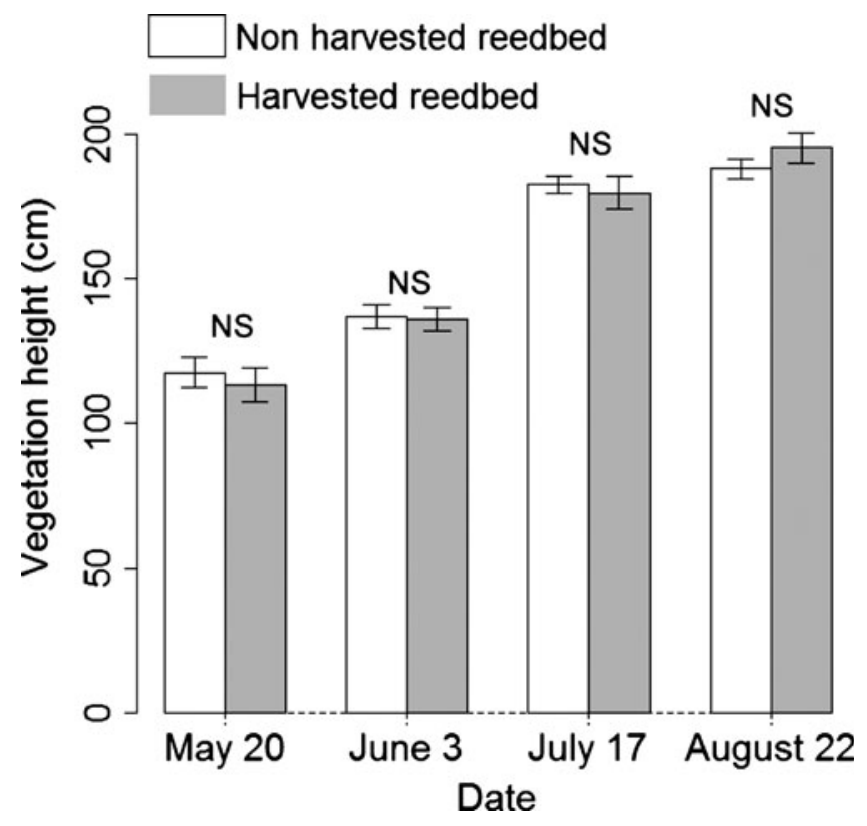

Figure 2. Mean vegetation height in harvested and non-harvested reedbeds from May to August 2010 based on green stems measured (except in May on non-harvested reedbeds when dry stems were higher than green ones and thus included in the data). Error bars show standard deviation from the mean. NS: non-significant difference.

nesting period started in the third week of May in both HA and NHA. We found no significant difference in the proportion of nests in each laying period between year $\left(\chi_{2}^{2}=0.73, P=0.69\right)$ or between habitat types $\left(\chi_{2}^{2}=1.09, P=0.58\right)$, suggesting a relatively homogeneous chronology of successive broods among years and no laying delay due to harvesting in 2010.

\section{Vegetation characteristics}

We found no significant difference in reed height between the harvested and non- harvested reedbeds for each month (Bonferroni's correction, $P=1$ for all tests, Figure 2).

\section{Causes of nest failure}

We determined the fate of 98 nests (Table 1 ). Causes of nest failure did not vary significantly between years for NHA $\left(\chi_{2}^{2}=2.27, P=0.32\right)$ nor between NHA and HA in $2010\left(\chi_{2}^{2}=5.27\right.$, $P=0.07)$. In NHA, predation was the most frequent cause of failures in 2009 and $2010(29 \%$ and

Table 1. Causes of nest failures for Reed Parrotbill during the year 2009-2010 in non- harvested (NHA) and harvested (HA) reedbeds. The unknown category includes nests found after their active period.

\begin{tabular}{llllllll}
\hline Year & Area & Weather & Predation & Abandoned & Unknown & Total failed & Total nests \\
\hline 2009 & NHA & 4 & 8 & 2 & 3 & 17 & 28 \\
2010 & NHA & 5 & 7 & 4 & 5 & 21 & 40 \\
2010 & HA & 6 & 5 & 1 & 6 & 18 & 30 \\
\hline
\end{tabular}


$18 \%$ respectively), followed by adverse weather ( $14 \%$ and $13 \%$ respectively) and abandonment ( $7 \%$ and $10 \%$ respectively). In HA, the main cause of failure was adverse weather $(20 \%)$ followed by predation (17\%) and abandonment $(3 \%)$.

\section{Nest survival and nesting success}

Among all models tested, those with only one variable provided a better fit than those with multiple covariates, and the constant-survival model had the best support (Table 2). Parameter estimates for all co-variables included zero, which indicates that none significantly influenced DSR (Table 3). The DSR of the constant-survival model was 0.961 and the average nest success was $32 \%$ in NHA and HA during the two years.

In NHA, the mean number of nestlings produced per successful nest was $2.5 \pm 1.0(n=11)$ in 2009 and $3.2 \pm 1.3(n=19)$ in 2010. In HA it was $3.5 \pm 0.9(n=13)$ in 2010. There was no significant difference between years (Student's t-test, $t_{28}=-1.47, P=0.15$ ) or habitats $\left(t_{30}=0.81, P=0.43\right)$

\section{Discussion}

Reed Parrotbill nesting density was significantly lower in the harvested reedbed than in the nonharvested reedbed, as previously reported (Boulord et al. 2010). However, our results showed that the nest success rate $(32 \%)$ was not influenced by harvesting, as all variables tested did not significantly affect daily nest survival in both harvested and non-harvested reedbeds and mean numbers of fledglings per nest were the same in the two types of reedbed. This can be explained by the fact that vegetation cover was not significantly different between the two areas during the whole breeding period and showed few variations in height within each site. As vegetation cover was high enough in the harvested reedbed, no breeding delay was observed. This result is slightly different from a previous study conducted in a different location in the Chongming Dongtan Nature Reserve, where a delay was observed (Boulord et al. 2010). At the latter site, the mean height of green stems was $72 \pm 20 \mathrm{~cm}$ in HA in mid-June, whereas it was $137 \pm 20 \mathrm{~cm}$ on 3 June in the present study and $111 \pm 36 \mathrm{~cm}$ in NHA at the end of May in the previous study, against $136 \pm 21 \mathrm{~cm}$ on 3 June in the present study. These results suggest that impact of harvesting on breeding initiation in harvested reedbeds depends on the growth rate of reeds and thus responses to environmental parameters such as nutrient supply, water level, and climate (Buttery and Lambert 1965, Haslam 1971, 1972, Cízková-Koncalová et al. 1996, Clevering 1998, Clevering et al. 2001). In

Table 2. Best fit models $(\triangle \mathrm{AICc}<2$ ) of Reed Parrotbill nest survival rate (DSR). The model S(.) represents the constant DSR model which only includes the intercept as parameter. Habitat = non-harvested or harvested reedbeds, $\mathrm{AICc}=$ Akaike's Information Criterion with correction for small sample size, $\triangle \mathrm{AICc}=$ difference between the given model and the best fit one, $\mathrm{K}=$ the number of parameters, $\mathrm{w}_{\mathrm{i}}=$ estimate of the likelihood of the model given the observed data; all models sum to 1.oo.

\begin{tabular}{llllll}
\hline Model & AICc & $\Delta$ AICc & $\mathrm{w}_{\mathrm{i}}$ & $\mathrm{K}$ & Deviance \\
\hline S(.) & 218.012 & 0.000 & 0.253 & 1 & 216.008 \\
Nest age & 219.400 & 1.388 & 0.126 & 2 & 215.388 \\
Habitat & 219.434 & 1.422 & 0.124 & 2 & 215.422 \\
Reed height & 219.781 & 1.769 & 0.105 & 2 & 215.769 \\
Year & 219.850 & 1.838 & 0.101 & 2 & 215.838 \\
Reed density & 219.863 & 1.851 & 0.100 & 2 & 215.851 \\
Linear time & 219.925 & 1.913 & 0.097 & 2 & 215.913 \\
Nearest nest & 220.008 & 1.996 & 0.093 & 2 & 215.996 \\
\hline
\end{tabular}


Table 3. Beta estimates, standard error (SE) and $95 \%$ confidence intervals (CI) for the best-fit models $(\triangle \mathrm{AICc}<2$, one parameter models) of Reed Parrotbill daily nest survival rate. AICc $=$ Akaike's Information Criterion with correction for small sample size.

\begin{tabular}{lcccr}
\hline Parameter & Estimate & SE & $95 \%$ CI & Upper \\
\cline { 3 - 5 } & & & Lower & 0.054 \\
Nest age & 0.016 & 0.020 & -0.023 & 0.899 \\
Habitat & 0.255 & 0.329 & -0.390 & 0.008 \\
Reed height & -0.003 & 0.005 & -0.013 & 0.514 \\
Year & -0.139 & 0.333 & -0.792 & 0.031 \\
Reed density & 0.005 & 0.013 & -0.021 & 0.005 \\
Linear time & 0.001 & 0.002 & -0.003 & 0.018 \\
Nearest nest & 0.001 & 0.009 & -0.016 & \\
\hline
\end{tabular}

reedbeds where common reed growth is lower, harvesting leads to a delay in egg-laying because the vegetation cover is too low in the early breeding season, as the average height of Reed Parrotbill nests is $79 \pm 23 \mathrm{~cm}(n=28$; unpubl. data).

Potential predators identified in both harvested and non-harvested stands included Long-tailed Shrike Lanius schach, Siberian weasel Mustela sibirica, and an unidentified snake (unpubl. data). Whereas reed harvesting has been shown to affect predation rates in Eurasian Reed Warbler and Sedge Warbler (Graveland 1999), we found no such effect on Reed Parrotbills, possibly because the overall vegetation cover was quite similar in harvested and non-harvested areas. The percentage of nests that failed due to weather did not differ between the harvested and nonharvested areas, but adverse weather seems to have an unusually high impact on Reed Parrotbill breeding success, as it represents $24-35 \%$ of total nest failures. For comparison, weather accounts for only $1.2 \%$ of nest failures in the Eurasian Reed Warbler, a species which also uses reed stems as nest support (Honza et al. 1998). This large disparity between the two species may be due to climatic differences between East European reedbeds and Chongming coastal reedbeds, where strong winds and rainstorms frequently occur in summer, making adverse weather a major cause of nest failure. Adverse weather thus contributes highly to nest success rate. It suggest that reedbeds that are too high are probably also unfavourable for the Reed Parrotbill and should explain why Ma (1988) observed lower individual densities in reedbeds with deep water such as irrigated reedbeds where reed growth is higher than in reedbeds with shallow water (Cowie et al. 1992, Ostendorp 1999, Vretare et al. 2001).

\section{Acknowledgements}

This study was supported by the Sciences and Technology Commission of Shanghai Municipality, the Science and Technology Ministry of China (no.1odz1200703; 10dz1211000; 2012BAK69B14), the Shanghai Landscaping and City Appearance Administrative Bureau (no. JB101503) and the French Centre National de la Recherche Scientifique (CNRS-INEE). Many thanks to Dr. Wang Zheng-huan and students Dong Bin and Wu Di for providing useful assistance in field investigation planning, and Pierre Fiquet, Laurent Brucy and Pascal Provost for their invaluable help and advice on bird capture and banding. We appreciate the improvements to the English made by Christina Riehl through the Association of Field Ornithologists' programme of editorial assistance. Captures, banding and blood sampling were carried out with the authorisation of the Shanghai Forestry Bureau and with the help of the staff of the Chongming Dongtan Nature Reserve, who are authorised by the National Bird Banding Center of China to carry out these activities. 


\section{References}

Akaike, H. (1973) Information theory and an extension of the maximum likelihood principle. Pp. 267-281 in B. N. Petran and F. Csáki, eds. International symposium on information theory. 2nd edition. Budapest, Hungary: Akadémiai Kiadi.

Baldi, A. and Moskat, C. (1995) Effect of reed burning and cutting on breeding bird communities. Pp. 637-642 in J. A. Bissonette and P. R. Krausman, eds. Integrating people and wildlife for a sustainable future. Bethesda, Maryland: The Wildlife Society.

Barbraud, C. and Mathevet, R. (2000) Is commercial reed harvesting compatible with breeding purple herons Ardea purpurea in the Camargue, southern France? Environ. Conserv. 27: 334-340.

Barbraud, C., Lepley, M., Mathevet, R. and Mauchamp, A. (2002) Reedbed selection and colony size of breeding purple herons Ardea purpurea in southern France. Ibis 144: 227-235.

Bibby, C. J. and Lunn, J. (1982) Conservation of reed beds and their avifauna in England and Wales. Biol. Conserv. 23: 167-186.

BirdLife International (2008) Paradoxornis heudei. In: IUCN 2010. IUCN Red List of threatened species. Available at: www. iucnredlist.org. Downloaded on 19 September 2010.

Boulord, A., Wang, T. H., Wang, X. M. and Song, G. X. (2010) Impact of reed harvesting and Smooth Cordgrass Spartina alterniflora invasion on nesting Reed Parrotbill Paradoxornis heudei. Bird Conserv. Internatn. 21: 25-35.

Burnham, K. P. and Anderson, D. R. (1998) Model selection and inference: a practical information-theoretic approach. New York: Springer-Verlag.

Burnham, K. P. and Anderson, D. R. (2002) Model selection and multi-model inference: a practical-theoretic approach. 2nd edition. New York: Springer-Verlag.

Buttery, B. R. and Lambert, J. M. (1965) Competition between Glyceria maxima and Phragmites communis in the region of Surlingham Broad. I. The competition mechanism. J. Ecol. 53: 163-181.
Cízková-Koncalová, H., Kvet, J. and Lukavská, J. (1996) Response of Phragmites australis, Glyceria maxima, and Typha latifolia to additions of piggery sewage in a flooded sand culture. Wetl. Ecol. Manage. 4: 43-50.

Clevering, O. A. (1998) The effects of nitrogen supply on growth and morphology of different stable and die-back populations of Phragmites australis. Aquat. Bot. 60: 1125.

Clevering, O. A., Brix, H. and Lukavská, J. (2001) Geographic variation in growth responses in Phragmites australis. Aquat. Bot. 69: 89-108.

Cowie, N., Sutherland, W. J., Ditlhogo, M. K. M. and James, R. (1992) The effects of conservation management of reed beds. II. The flora and litter disappearance. J. Appl. Ecol. 29: $277-284$.

Dinsmore, S. J., White, G. C. and Knopf, F. L. (2002) Advanced techniques for modeling avian nest survival. Ecology 83: 3476-3488.

Graveland, J. (1999) Effect of reed cutting on density and breeding success of Reed Warbler Acrocephalus scirpacaeus and Sedge Warbler A. schoenobaenus. J. Avian Biol. 30: 469-482.

Haig, S. M., Belthoff, J. R. and Allen, D. H. (1993) Population viability analysis for a small population of Red-Cockaded Woodpeckers and an evaluation of enhancement strategies. Conserv. Biol. 7: 289-301.

Haslam, S. M. (1971) Community regulation in Phragmites communis. II. Mixed stands. J. Ecol. 59: 75-88.

Haslam, S. M. (1972) Biological flora of the British Isles. Phragmites communis Trin. J. Ecol. 6o: 585-610.

Honza, M., Øien, I. J., Moksnes, A. and Røskaft, E. (1998) Survival of reed warbler Acrocephalus scirpaceus clutches in relation to nest position. Bird Study 45: 104-108.

Kristiansen, J. N. (1998) Nest site preference by greylag geese Anser anser in reedbeds of different harvest age. Bird Study 45:337343.

Ma, S. Q. (1988) Studies on the population ecology of the Chinese crowtit. Zool. Res. 9: 217-224. (In Chinese). 
Ostendorp, W. (1999) Management impacts on stand structure of lakeshore Phragmites reeds. Int. Rev. Hydrobiol. 84: 33-47.

Poulin, B. and Lefebvre, G. (2002) Effect of winter cutting on the passerine breeding assemblage in French Mediterranean reedbeds. Biodivers. Conserv. 11: 1567-1581.

Rotella, J. J. (2009) Nest survival models. Chapter 17 in E. Cooch and G. C. White, eds. Program MARK: a gentle introduction. 9th edition. http://www.phidot.org/ software/mark/docs/book/. Downloaded on 19 September 2010.

Tian, B., Zhang, L. Q., Wang, X. R., Zhou, Y.X. and Zhang, W. (2010) Forecasting the effects of sea-level rise at Chongming Dongtan Nature Reserve in the Yangtze Delta, Shanghai, China. Ecol. Eng. 36: 1383-1388.
Trnka, A. and Prokop, P. (2006) Reedbed structure and habitat preference of reed passerines during the post-breeding period. Biol. Brat. 61: 225-230.

Valkama, E., Lyytinen, S. and Koricheva, J. (2008) The impact of reed management on wildlife: a meta-analytical review of European studies. Biol. Conserv. 141: 364-374.

Vretare, V., Weisner, S. E. B., Strand, J. A. and Granéli, W. (2001) Phenotypic plasticity in Phragmites australis as a functional response to water depth. Aquat. Bot. 69: 127-145.

White, G. C. and Burnham, K. P. (1999) Program MARK: survival estimation from populations of marked animals. Bird Study 46: 120-139.

Zheng, G. (2002) A checklist on the classification and distribution of the birds of the world. Beijing, Science Press.

\section{ANTHONY BOULORD}

Muséum National d'Histoire Naturelle, UMR 7204 MNHN-CNRS-UPMC, CRBPO, CP 51, 55 Rue Buffon, 75005 Paris, France and Shanghai Key Laboratory of Urbanization and Ecological Restoration, School of Life Sciences, East China Normal University, $3663 \mathrm{~N}$ Zhongshan Rd, Shanghai, 200062, P.R. China.

\section{FRÉDÉRIC JIGUET}

Muséum National d'Histoire Naturelle, UMR 7204 MNHN-CNRS-UPMC, CRBPO, CP 51, 55 Rue Buffon, 75005 Paris, France.

\section{ZHANG MEI, WANG TIAN-HOU*, WANG XIAO-MING}

Shanghai Key Laboratory of Urbanization and Ecological Restoration, School of Life Sciences, East China Normal University, 3663 N Zhongshan Rd, Shanghai, 200062, P.R. China.

*Author for correspondence; e-mail: thwang@bio.ecnu.edu.cn

Received 26 April 2011; revision accepted 12 July 2011; Published online 5 December 2011 